involved children below the age of 6 years. Only $8(5 \%)$ deaths happened in the 50-65 years category.

Contribution to the Field Understanding the age and gender distribution of RCC may help in making interventions to reduce RCC, a preventable cause of mortality in Lusaka. The children, young adults and elderly need to be targeted reduce the RCC carnage in the city. Mortuary data can help monitor, evaluate and inform policies.

\section{9 \\ AGE AND GENDER DISTRIBUTION OF ROAD CAR CRASH
MORTALITIES BETWEEN JUNE 2007 AND NOVEMBER 2008 IN LUSAKA, ZAMBIA}

doi:10.1136/injuryprev-2012-040590u.29

R Mtonga. Mthunzi Medical Centre, Lusaka, Zambia

Background Road Car Crashes (RCC) are the leading cause of injury-related deaths in Lusaka. From a total of 614 injury-related deaths during the study, 166(27\%) with 145(87\%) males and 21 $(13 \%)$ were due to RCC. Predominantly children and young adults were affected at $116(87 \%)$.

Objective To Audit Road Car Crash mortality between June 2007 and November 2008 captured at the Lusaka Death Registry.

Methods This retrospective study, done at the Lusaka City Death Registry, employed Certificates of Deaths, Burial Permits and Postmortem record involving RCC in Lusaka.

Results A total of 166 made up 145 Males and 21 Females RCC deaths occurred. The 20-35 year bracket contributed 71(43\%) with $26(16 \%)$ deaths in seniors 65 years of age or older. Adults between 36 and 50 years brought in $32(19 \%)$ deaths, 24(14\%) happened in school going children between 7 and 19 years of age while $21(13 \%)$ 